\title{
Tensile Testing Assay for the Measurement of Tissue Stiffness in Arabidopsis Inflorescence Stem \\ Kouki Yoshida ${ }^{1, \#, ~ S h i n g o ~ S a k a m o t o 2, ~ \# ~ a n d ~ N o b u t a k a ~ M i t s u d a 2, ~ * ~}$
}

\author{
${ }^{1}$ Technology Center, Taisei Corporation, Yokohama, Kanagawa, Japan; 2 Plant Gene Regulation \\ Research Group, Bioproduction Research Institute, National Institute of Advanced Industrial Science \\ and Technology (AIST), Tsukuba, Ibaraki, Japan \\ *For correspondence: nobutaka.mitsuda@aist.go.jp \\ \#Contributed equally to this work
}

[Abstract] Lignocellulosic biomass is a versatile renewable resource for fuels, buildings, crafts, and biomaterials. Strategies of molecularly designing lignocellulose for industrial application has been developed by the discoveries of novel genes after the screenings of various mutants and transformed lines of Arabidopsis whose cell walls could be modified in the inflorescence stem, a model woody tissue. The mechanical properties are used as a quantitative index for the chemorehological behavior of the genetically modified cell wall in the tissue. This parameter can be measured with tensile or bending tests of tissue explants, the vibration analysis of tissue behavior or using atomic force microscopy to probe the tissue surface. Here, we describe in detail the procedure to determine the stiffness of methanolfixed, rehydrated and pronase-treated inflorescence explants with a tensile testing machine based on classical methods for the determination of cell wall extensibility.

Keywords: Arabidopsis, Cell wall, Compliance, Inflorescence stem, Mechanical properties, Stiffness, Tensile tests, Young's modulus

[Background] Plant biomechanics can be measured with different methods such as a tensile test (Burgert et al., 2003; Cosgrove, 2011), a bending test (Shah et al., 2017), vibration analysis (Niklas and Moon, 1988, Nakata et al., 2018) and atomic force microscopy (Radotić et al., 2012). These techniques are available to quantify the stiffness and strength properties of materials. Stiffness is defined by the force required to displace (stretch) the material over a unit length, while the strength is regarded as the amount of force required to ultimately rupture the material. The stiffness of a structure is affected by the material properties such as lignocellulosic composition and the bio-structural geometry such as a thickness of cell wall (Shah et al., 2017). The biomechanical tests designed to measure these properties are frequently used in timber grading for commercial sale as well as in tree breeding programs to select and breed superior trees with increased stiffness and strength. Such tests can be also used in Arabidopsis thaliana to identify candidate genes with effects on strength and stiffness in mutant screening as a wood model (Strabala and MacMillan, 2013, Figures 1A-1C). In fact, the tensile test was used to estimate the stiffness of inflorescence stems in Arabidopsis in our previous study (Sakamoto et al., 2018). The protocol in this article provides the procedure to measure the stiffness of mature regions of Arabidopsis inflorescence stem with a tensile testing machine (Figure 1D). It is based on the method 
to measure the cell wall extensibility (compliance) of tissue explants of dicot seedling stems and monocot coleoptiles (Olson et al., 1965; Cleland, 1967) performed intensively between the 1960s and the 1980s (Taiz, 1984; Masuda, 1990). This has been optimized to the determination of the stiffness of inflorescence stem in Arabidopsis and described in this article.

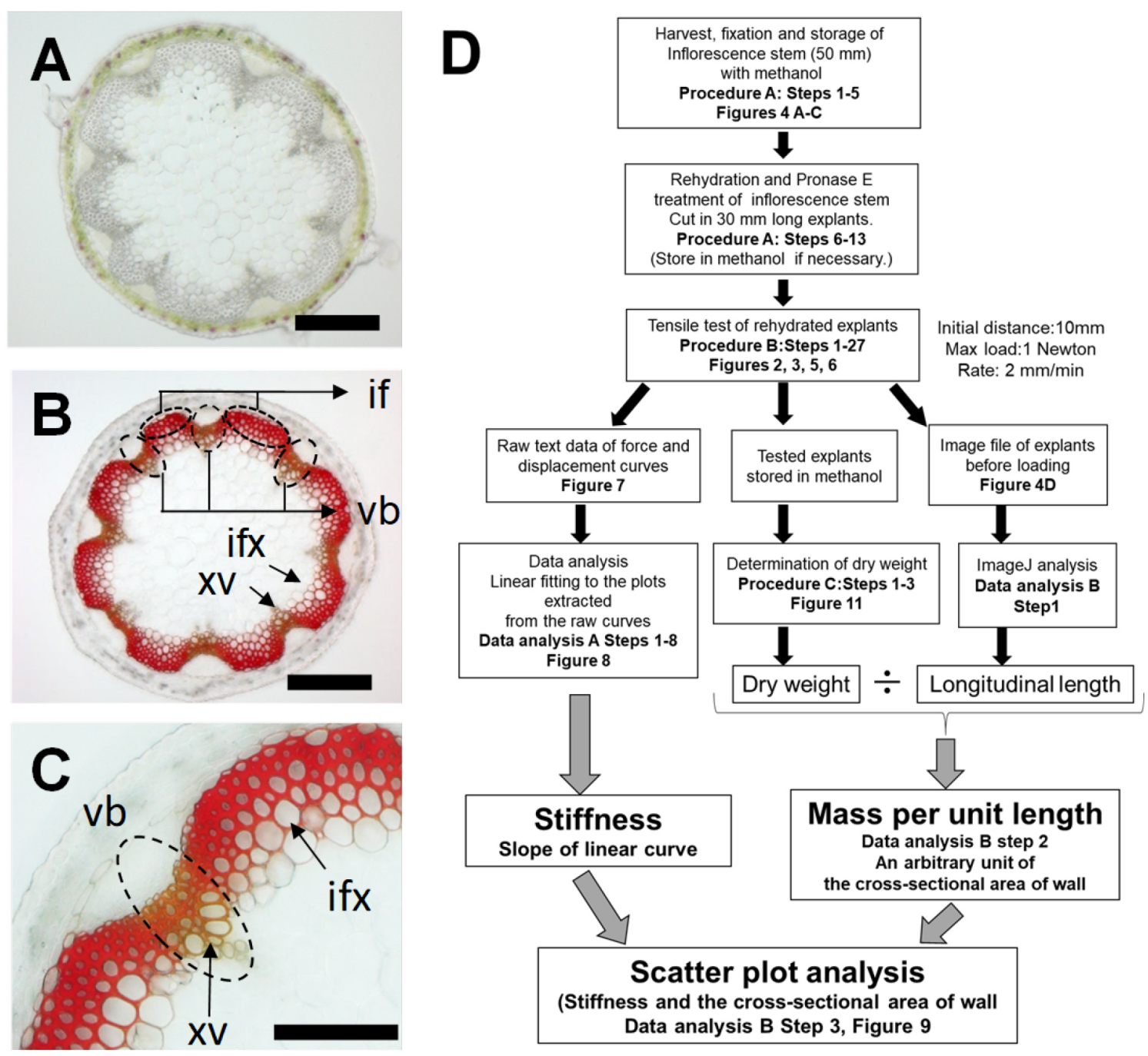

Figure 1. Overview of tensile test to measure the tissue stiffness of a model woody tissue in

Arabidopsis. A. Cross sections of mature regions of Arabidopsis inflorescence stem as a model woody tissue. B and C. Stained cross section with Mäule reagent. Interfascicular fiber (If), Vascular bundles (vb), xylem vessels (xv), interfascicular xylem fibers (ixf). Bars indicate $200 \mu \mathrm{m}$. D. Flow chart of tensile testing assay for the measurement of tissue stiffness in Arabidopsis inflorescence stem.

\section{Materials and Reagents}

1. Transparent tape

2. PYREX ${ }^{\circledR} 55 \mathrm{ml}$ Screw Cap Culture Tubes with PTFE Lined Phenolic Caps, 25 x $150 \mathrm{~mm}$ 
(Corning Co. Ltd., catalog number: 9826-25)

3. Plastic transfer pipet (Transparent LDPE, $4 \mathrm{ml}$, Thin stem, Thermo Fisher Scientific Co. Ltd., catalog number: 13459118)

4. Razor blade (Hi-Stainless Single Edge Blade, FEATHER Safety Razor Co. Ltd., catalog number: FHS-10)

5. Plastic Petri dish (90 mm x $14.2 \mathrm{~mm}$ ) (Thermo Fisher Scientific Co. Ltd., catalog number: 5184E)

6. Kimtowel wipes (Kimberly-Clark Co. Ltd.)

7. Kimwipe paper strips (Kimberly-Clark Co. Ltd., ca. $2 \mathrm{~mm} \times$ ca.10 mm in length) (Figure 2)

8. $2 \mathrm{ml}$ microtube (Eppendorf Co. Ltd., catalog number: 0030120094)

9. Aluminum foil

10. Inflorescence stem of 8 week-old Arabidopsis thaliana

11. Methanol (Kishida Chemical Co. Ltd. Japan, catalog number: 000-48666)

12. $\mathrm{KH}_{2} \mathrm{PO}_{4}$ (Nakalai Co. Ltd. Japan, catalog number: 09582-75)

13. $\mathrm{K}_{2} \mathrm{HPO}_{4}$ (Nakalai Co. Ltd. Japan, catalog number: 09583-65)

14. Pronase E (PE) from Streptomyces griseus (Product name is "Actinase E". Nacalai Co. Ltd. Japan, catalog number: $29003-51$ ), store at $4{ }^{\circ} \mathrm{C}$

15. SDW: Sterilized ultrapure water (e.g., Milli-Q)

16. Potassium phosphate buffer for PE solution (see Recipes)

17. PE solution (see Recipes)

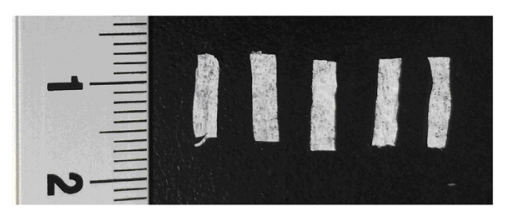

Figure 2. Kimwipe paper strips used to fix sample with the clamps (ca. $2 \mathrm{~mm} \times 10 \mathrm{~mm}$ in length, hand-made)

\section{Equipment}

1. Tensile testing machine for max. 500 Newton (N) (T.S.E. Co. Ltd. Yokohama, Japan, Auto Com Series, catalog number: AC-500N-CM, Figure $3 \mathrm{~A}$, see Note 1)

2. Load cell for max.10 N (T.S.E. Co. Ltd., Catalog number: TC-10N-B) (Figure 3A)

3. Upper and lower fiber clamps in lever action (Figures 3B and 3C, Clip jaw 5N, A \& D Co. Ltd., Tokyo, Japan, catalog number: J-TZM-5N) 


\section{bio-protocol
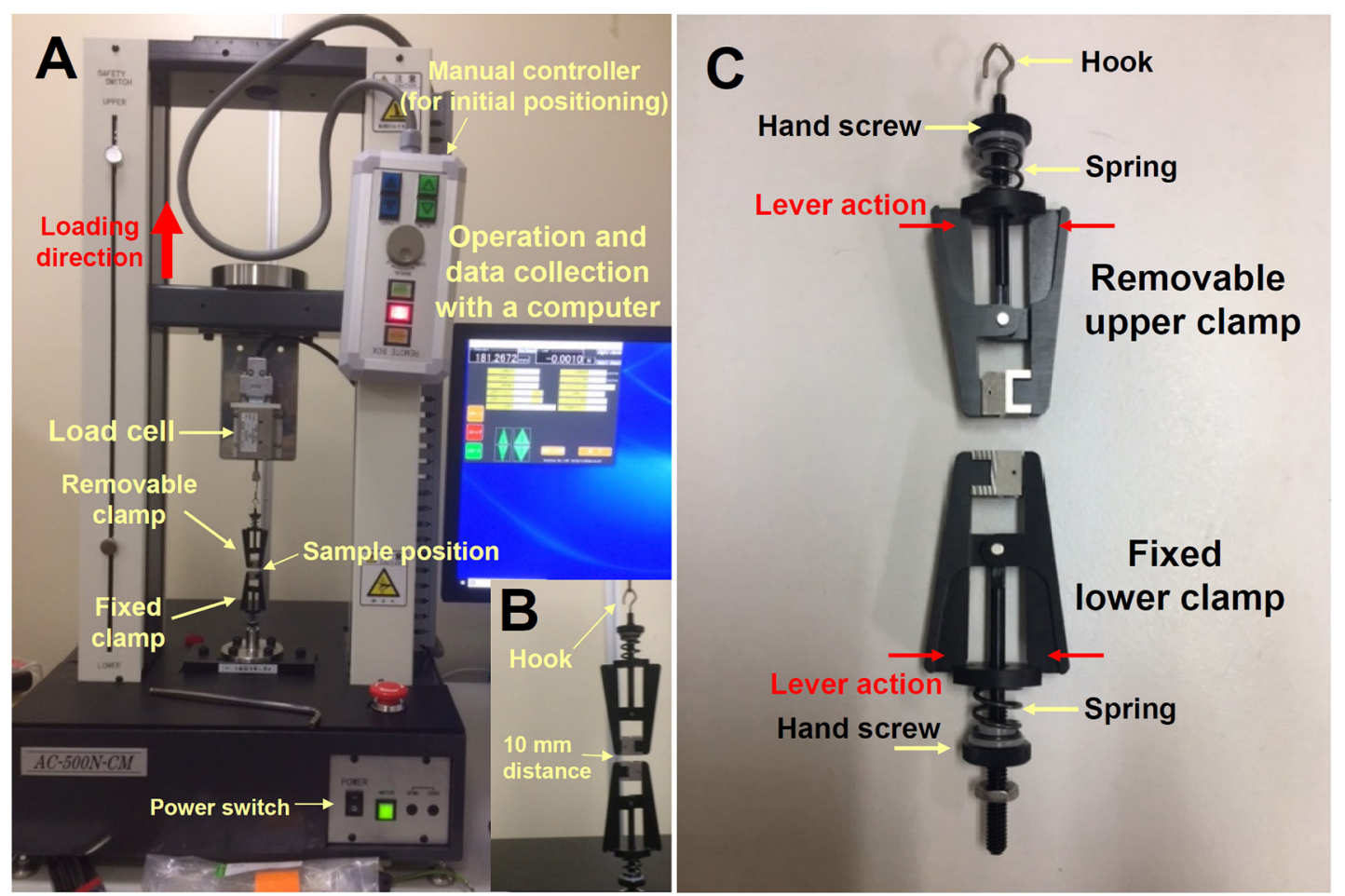

Figure 3. Tensile testing machine and its clamps. A. Tensile testing machine for maximal $500 \mathrm{~N}$ force. B. Removable clamp with a hook and fixed clamp. Set the zero point of the load in this position of the removable clamp. C. Top-removable and bottom-fixed fiber clamps. The clamp can be opened by lever action and sample should be fixed with hand screw tightly.

4. Oven $\left(37^{\circ} \mathrm{C}\right.$ or $60^{\circ} \mathrm{C}$, EYELA Co. Ltd., Japan, Forced Air Flow Oven, WFO420)

5. Water bath (TR-1 $\alpha$, ASONE Co. Ltd., Japan, catalog number: 1-5832-31)

6. Chemical fume hoods

7. Analytical balance (Mettler Toledo Co. Ltd., Balance XPR26, catalog number: 30355476)

8. Universal Anti-Static Kit U-electrode (Mettler Toledo Co. Ltd., catalog number: 11107767)

9. Sharp-Pointed Dissecting Scissor (Thermo Fisher Scientific. Co. Ltd., catalog number: 08-940)

10. Digital camera

11. Ruler (up to $150 \mathrm{~mm}$ )

12. Tweezer (EBL Co. Ltd., model: \#202)

\section{Software}

1. Operation and analysis software for the tensile testing machine (T.S.E. Co. Ltd., Yokohama, Japan, UTPS-STD Single for windows 10, English version is available)

2. Microsoft Excel (https://products.office.com/en-au/excel) 


\section{Procedure}

A. Plant material preparation (requires 2-3 days after the harvest of tissue)

1. Excise the basal parts (roughly $30 \mathrm{~mm}$ from bottom of stem) of inflorescence stems from 8 weekold Arabidopsis with scissors (Figures $4 \mathrm{~A}-4 \mathrm{C}$ ) and immediately and completely submerged the whole part of explant in $40 \mathrm{ml}$ methanol in PYREX ${ }^{\circledR} 55 \mathrm{ml}$ screw cap culture tubes. Plants are grown under 16 -h light $\left(60-80 \mu \mathrm{mol} \mathrm{m}^{-2} \mathrm{~s}^{-1}\right) / 8-\mathrm{h}$ dark cycle in a constant $23^{\circ} \mathrm{C}$ plant room with no humidity control.

Note: More than fifteen explants of inflorescence stem are necessary for the evaluation of one plant line (see Note 2).
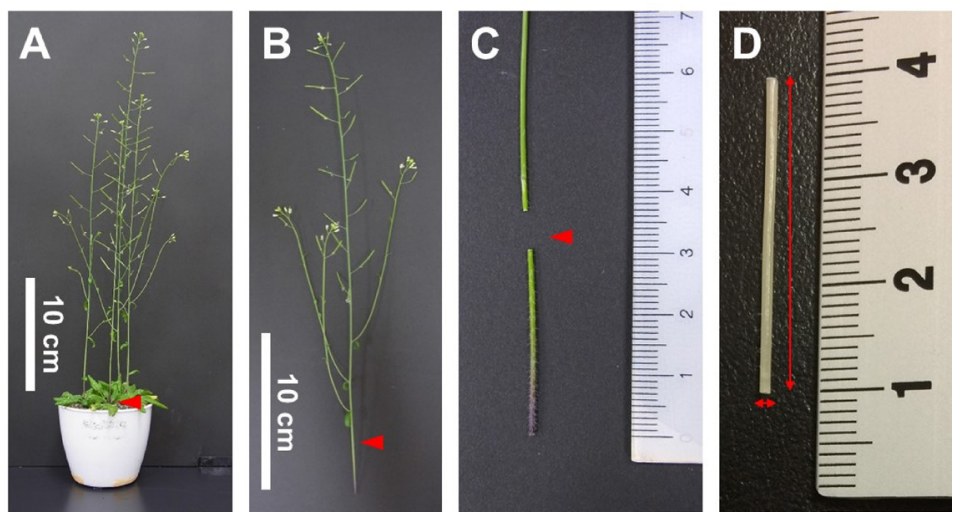

Figure 4. Stem segment taken from basal part of the inflorescence stem of Arabidopsis.

A. Eight-weeks old plant grown in soil. The basal end was cut at the position of red arrowhead with a pair of scissors. B. Harvested and fresh inflorescence stem. Excised stem segment which should be cut at the position of arrowhead. All branches should be removed. C. Digested fresh segment of inflorescence stem which should be submerged into methanol immediately. D. 30 mm-length inflorescence-stem segment after boiled in methanol, rehydration and Pronase E. Treatment. Longitudinal and vertical lengths of each sample should be determined later by Image J.

2. Close the cap of culture tube tightly to avoid a methanol explosion from the tube during the heat treatment described in Step A3.

3. Put the Pyrex glass tubes containing explants dipped in methanol into the water bath at $80{ }^{\circ} \mathrm{C}$ in the chemical fume hood. Incubate them for $15 \mathrm{~min}$ (see Note 3).

4. After cooling the tubes at room temperature, discard the green-colored methanol extract and add $40 \mathrm{ml}$ of fresh methanol to the glass tube.

5. Repeat Steps $\mathrm{A} 3$ and $\mathrm{A} 4$ until explants become white at least more than five times.

6. Wash the methanol-fixed explants with SDW more than five times to remove methanol.

Note: Make sure all explants sink to the bottom in SDW. If some explants are floating in the tube, stand for 5 min and change SDW again. 
7. Discard SDW completely in the tube with a plastic transfer pipet.

Note: Don't touch the tissue explants by a transfer pipet to avoid destruction of tissues.

8. Add $40 \mathrm{ml}$ of the Pronase $\mathrm{E}$ (PE) solution (see Recipes), which is pre-incubated for $2 \mathrm{~h}$ at $37^{\circ} \mathrm{C}$ before use, to a glass tube.

Note: Pre-incubation is essential to deactivate the glycosyl hydrolase contaminants in the PE products. Make sure all explants sink to the bottom of $50 \mathrm{ml}$ glass tube in the PE solution.

9. Incubate the glass tube containing explants in PE solution with tightly capped lids in the oven at $37^{\circ} \mathrm{C}$ for $18 \mathrm{~h}$ (see Note 4 ).

10. Discard PE solution from the tube.

11. Wash the PE-treated explants with SDW more than three times and remove the remaining solution from the $50 \mathrm{ml}$-glass tube as much as possible with a plastic transfer pipet.

Note: Don't touch the tissue explants with a transfer pipet to devoid any destruction of tissues.

12. Trim the basal end of explants with a razor blade to make them exactly $30 \mathrm{~mm}$ in length (Figure 4D).

13. Determine the force and displacement curve of inflorescence explant (Procedure B) or store the $30 \mathrm{~mm}$-length tissue explants in methanol at room temperature until use. Wash the explants with SDW at least three times before the experiment if the explants are stored in methanol (Step 10 of Procedure B)

B. Determination of the force and displacement curve of inflorescence explants (ca. 5 min for the measurement of one sample).

1. Turn on the tensile tester and the computer (Figure 3A)

2. Set the "tensile test mode" in the operation software and the data sampling method to X-T mode with the maximal resolution of distance $(0.001 \mathrm{~mm})$ according to the manufacturer's manual.

3. Set the initial distance between upper (top) and lower (bottom) fiber clamps to $10 \mathrm{~mm}$ after setting the upper clamp (without sample) to the original position (Figures $3 \mathrm{~B}$ and $6 \mathrm{~F}$ ).

4. Calibrate the load cell (at both $0 \%$ and $50 \%$ of $10 \mathrm{~N}$ ) without removing the upper removable clamp according to the manufacturer's manual (Figure 3B).

5. Set the speed of upper movable clamp to $2 \mathrm{~mm} / \mathrm{min}$.

6. Set the maximum load to $1 \mathrm{~N}$ (ca. $100 \mathrm{~g}$ ) which is the load when the test is finished.

7. Set the program to return upper movable clamp to the initial position after the test.

8. Designate the data file format and enter the plant-line name of samples and the test number.

9. Prepare $2 \mathrm{ml}$-micro tubes containing $2 \mathrm{ml}$ fresh methanol in tube rack. Protect the tube label (plant line name and test number) from methanol with transparent tape.

10. If samples have been stored in methanol prior to the test, wash and rehydrate the $30 \mathrm{~mm}$ length explants by at least five changes of SDW. Make sure all tissue explants sink to the bottom of the glass tube after the rehydration.

11. Transfer tissue explants into the plastic Petri dish containing $40 \mathrm{ml}$ SDW from the glass tube and keep them in the SDW until needed for the test. 
12. Take a tissue explant out from the SDW and immediately take a photograph of the tissue explant with a ruler and the label of the test number and sample name with a digital camera (Figure 4D). Determine the longitudinal and vertical lengths of explants later.

Note: Avoid drying the sample from Steps B12 to B24.

13. Put the tissue explant on Kimtowel wiper to remove excess water on the surface of the explant.

14. Put the $2 \mathrm{~mm} \times$ ca. $10 \mathrm{~mm}$ strips of Kimwipe on both ends of the tissue explant (Figure 5A). Fold each paper strip at the middle to hold the both edges of the tissue explant (Figure 5B).

Note: These paper strips are necessary to prevent tissue slippage in the fiber clamps during the test.

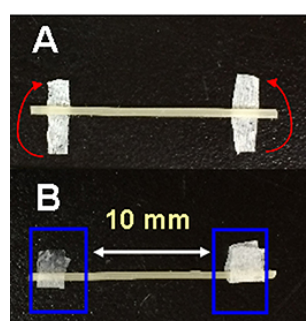

Figure 5. Two small paper strips of Kimwipe are used to prevent the sample slippage in the clamps. A. After putting two paper strips under the sample, fold two paper fragments in the middle to the direction of red arrows. B. After that, fix the parts of the sample, which are indicated by blue boxes, with the upper and lower clamps.

15. Fix one side of the paper strip-covered parts of the explant (Figure 5B) with the removable clamp by the lever action. Make sure the longitudinal axis of the tissue is vertically positioned at the center of the upper clamp (Figures 6A and 6B).

16. Tighten the hand screw of the upper clamp to fix the tissue more. Do not tighten the screw completely to avoid destruction of the tissue (Figure $3 \mathrm{C}$ ). Make sure the top-removable clamp fitting to the sample without any gap (upper arrowhead in Figure $6 \mathrm{C}$ ) and any distortion (lower arrowhead and white dashed lines in Figure 6C). The gap and distortion could cause slightly wavy fluctuation of force extension curve during the tensile test. If gap and distortion are found, adjust the clamps and the sample by pushing the attachments of clamp with your thumbs (Figures $6 \mathrm{D}$ and $6 \mathrm{E}$ ). This adjustment is also necessary to fix the sample with the bottom-fixed clamp in Steps B18 and B19. 

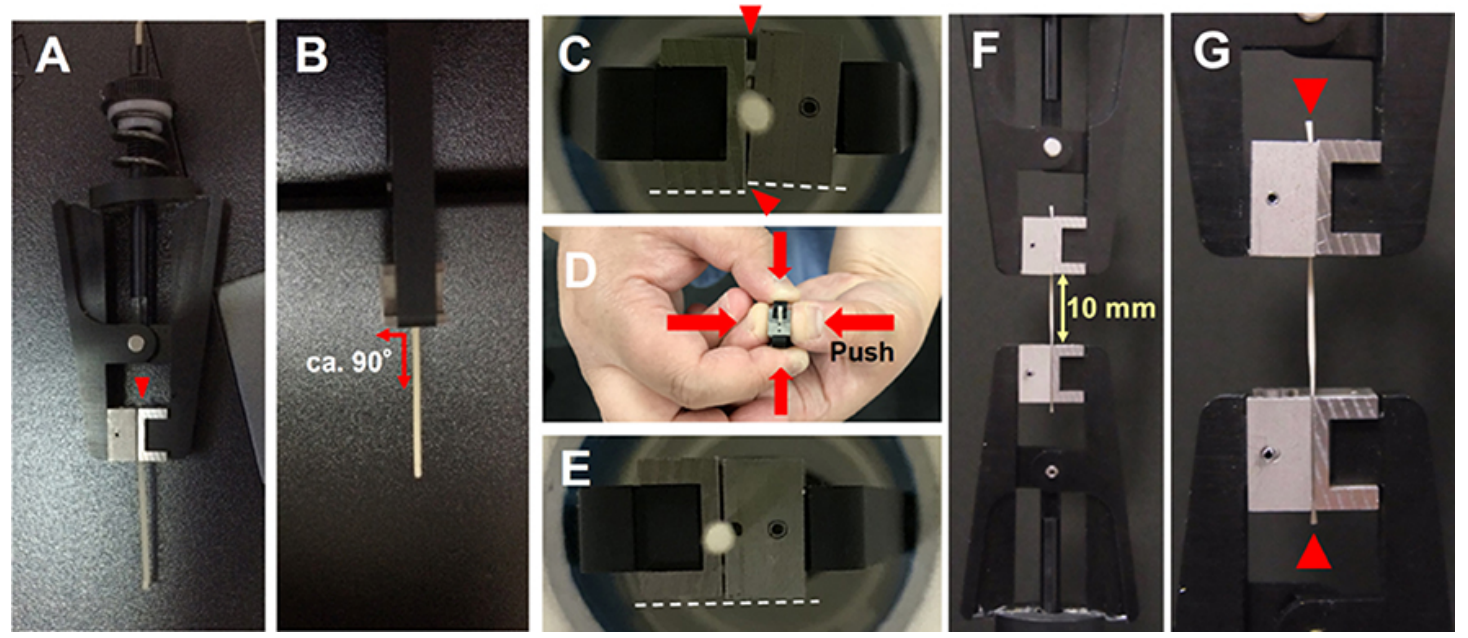

Figure 6. Tissue sample fastened between two clamps. A. Fix the sample with the upper removable clamp first (front view). See the position of one end of sample (Arrowhead). B. Make sure the angle between the sample and the edge of the upper clamp is ca. 90 degree (Side view). C-E. Make sure the top-removable and bottom-fixed clamps fitting to the sample without any gap (indicated by the upper arrowhead in $\mathrm{C}$ ) and any distortion (indicated by the lower arrowhead and white dashed line in C). F and G. After hanging the upper clamp with the sample on the hook of the load cell, fix the sample with the lower clamp. Make sure both upper and lower ends of the sample protruding from clamps a little (Arrowheads in $G$ ).

17. Hang the upper clamp with the explant on the hook of the loading cell.

18. Fix another side of the paper strip-covered part of the explant with the lower clamp (Figure 6F). Make sure the longitudinal axis of the tissue is vertically positioned at the center of the lower clamp as for the upper clamp. Both ends of the sample should extrude a little from the clamps (Arrowheads in Figure 6G).

19. Tighten the hand screw of the lower clamp to fix the tissue securely (Figure $3 \mathrm{C}$ ). Do not tighten the screw completely to avoid destruction of the tissue (see Note 5).

20. Make sure the load between two clamps is almost $0 \mathrm{~N}$ (From -0.042 to $0.0183 \mathrm{~N}$, Mean and standard deviation: $-0.0059 \mathrm{~N} \pm 0.0092$ in our experiments) in order to avoid prestreching before the test. A strong prestrech could cause the plastic deformation of the sample before the estimation of stiffness (Cleland, 1967).

21. If the load value before the test is not ignorable, loosen the hand screw of the lower clamp slightly. Repeat Steps B18 and B19 to get the load value close to 0. Alternatively, change the distance between two clamps to shorter than $10 \mathrm{~mm}$ with a manual controller (Figure $1 \mathrm{~A}$ ) to let the load value close to zero without touching the lower clamp $(-0.01 \mathrm{~mm}$ to $0.05 \mathrm{~mm}$ in our experiments). In the latter case, record the changed distance between two clamps.

22. Start loading the sample to $1 \mathrm{~N}$ by lifting the upper clamp.

23. After reaching to $1 \mathrm{~N}$, the loading should be stopped mechanically and the upper clamp should return to the initial position (10 $\mathrm{mm}$ distance) immediately. Prepare the next sample during this 
process (from Step B12).

24. After the return of the upper and movable clamp to its original position, remove the tested sample from the upper and lower clamps by loosening the hand screws and levering action.

25. Store each tested sample in methanol in a numbered $2 \mathrm{ml}$-micro tube.

26. Repeat these steps (from Step B12 to Step B25) for all samples in one plant line.

27. Store the series of all data for one plant line and export the relationship between displacement $(\mathrm{mm})$ and load $(\mathrm{N})$ for all samples in text format. The text data files should be analyzed with Microsoft Excel software or equivalent software (see Data analysis).

28. Turn off the tensile testing machine and the computer.

C. Determination of the sample dry weight

1. Discard methanol from the $2 \mathrm{ml}$-microtubes containing a tissue explant (stored in Step B24) with a plastic transfer pipet avoiding destruction of the sample.

2. Place the $2 \mathrm{ml}$-microtubes in the oven at $60^{\circ} \mathrm{C}$ for 2 days without capping but with a small piece of aluminum foil sheet to prevent dust contamination.

3. Weigh the dried tested sample with an analytical balance equipped with an anti-static apparatus and the custom-made wind-proof cover (Note 6).

\section{Data analysis}

A. Determination of inflorescence stiffness

1. Open the text data file generated at the "Step 27" of Procedure B with Microsoft Excel or equivalent software. (An example of the text data file in our experiments is provided as a supplemental text files "Col0".)

2. Highlight all cells containing data. In our data, the first column (A) contains values of displacement $(\mathrm{mm})$, and the second column $(B)$ contains values of force $(\mathrm{N})$ in the single tensile test and draw scatter plot using the software function.

3. Observe the force and displacement curves (Figure 7). The curve should have two phases. At first, the displacement is accompanied by little increase of the load. This is, at least in part, due to some slack existing in the explant when it was fixed between the clamps and thus should be removed. Beyond a certain point, load increases in a linear manner as displacement proceeds (Cleland, 1967). Use the force and displacement values in the linear range to calculate stiffness.

4. Draw the curves for all tests and compare the force ranges in a linear manner to extract the representative linear range. For example, we estimated that the representative linear force range was between 0.6 to $0.8 \mathrm{~N}$ in our experiment (Figure 7). 


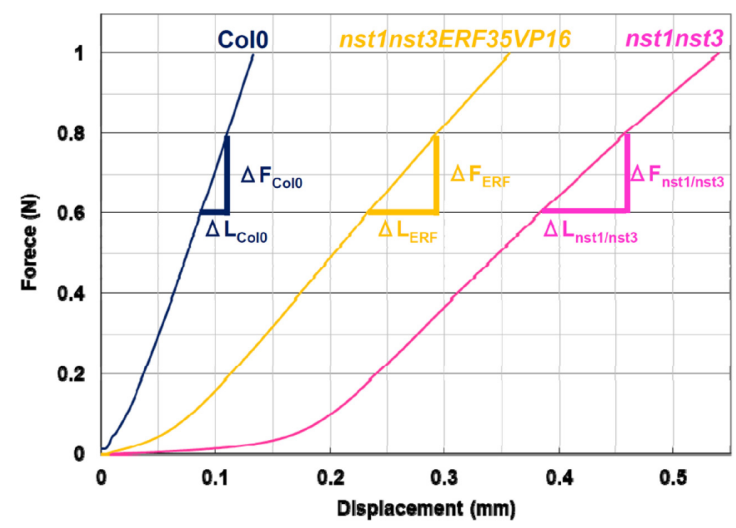

Figure 7. Force and displacement curves for inflorescence explants in different plant lines of Arabidopsis. Col0: wild type, nst1nst3: double knockout mutant of NST1 and NST3 genes (Mitsuda et al., 2007), nst1nst3ERF35VP16: NST3 promoter-driven ERF035 gene with VP16 activation domain in the double knockout mutant (Sakamoto et al., 2018).

5. Highlight the cells of displacement column and force column in the fixed force range (for example, from 0.6 to $0.8 \mathrm{~N}$ ) and create a scatter plot.

6. Add the linear fit (a straight line fit) using the software function. In Microsoft Excel, click once anywhere inside the graph area and select the "Layout" tab from "Chart Tools". Click "Trendline" icon and select the "Linear Trendline" option.

7. To show the equation, click "Trendline" and select "More Trendline Options..." Then check the "Display Equation on chart" and "Display R-squared value on chart" boxes. (Figure 8).

8. The slope of the equation indicates stiffness ( $\mathrm{N} / \mathrm{mm}$, Note 7). Examine the fitness of a linear plot with R-squared value ( $R^{2}: 0.9969$ to 1 in our experiment).

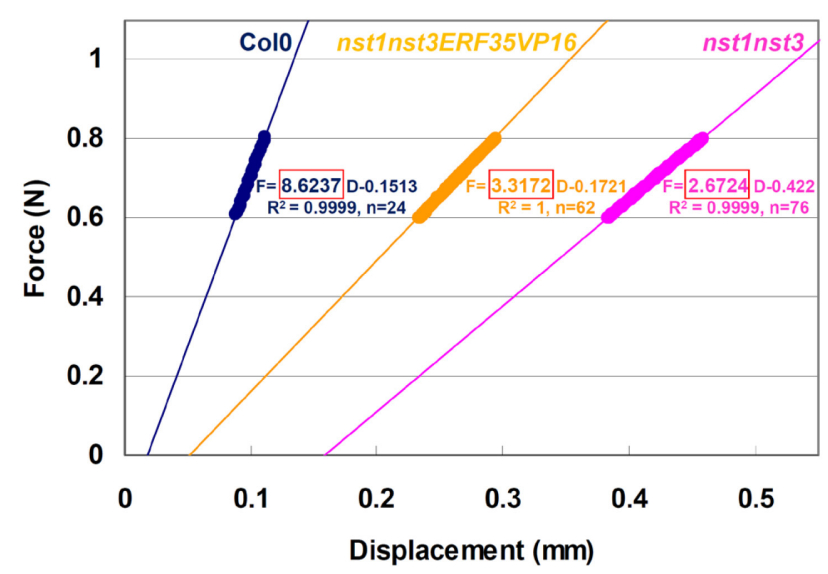

Figure 8. Linear plots and equations of force $(F)$ and displacement (D) curves prepared by Microsoft Excel. Round-shaped actual plots indicate the values between 0.6 and $0.8 \mathrm{~N}$, which were used for the linear fit. "n" indicates the number of used plots. The slope in the equation surrounded by the red box gives the stiffness of each sample. $R$ square-values are also indicated. 
B. Determination of mass per unit length of tissue explants and the estimation of the effects of introduced or mutated genes on the inflorescence-stem stiffness

1. Determine the longitudinal and the vertical length of tissue explants from the photograph taken at Step 12 of Procedure B (Figure 4D).

2. Divide the dry weight (obtained at the Step 3 of Procedure $C$ ) by the longitudinal length of each tissue explant to obtain mass per unit length.

3. Plot the mass per unit length and the stiffness of the investigated plant lines on a graph to see if there is any trend (i.e., effects of genes on the material properties such as cell wall compositions and/or the bio-structural geometry such as wall thickness, Figure 9).

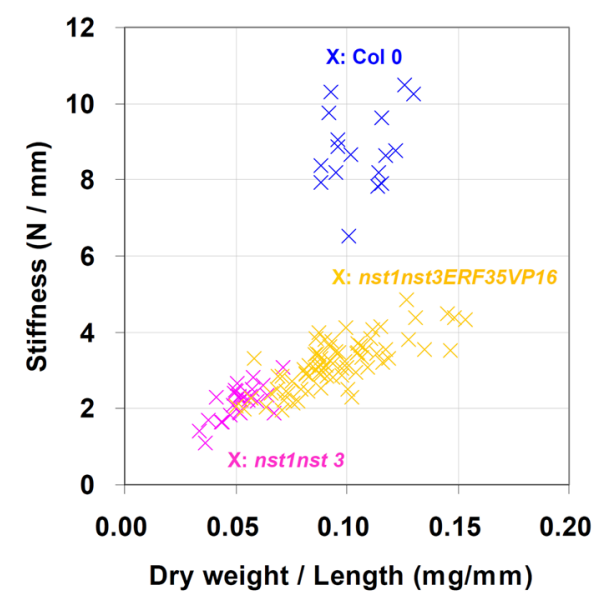

Figure 9. Scatter plot between dry weight/length and force/extension (stiffness) of different genotype plants. Wild-type $(n=17$ biologically independent samples), $n$ st1nst3 $(n=$ 27 biologically independent samples) and nst1nst3 NST3pro::ERF035-VP16 $(\mathrm{n}=76$ biologically independent samples) (Sakamoto et al., 2018).

\section{Representative data}

One set of raw text data of the force and displacement curve of wild-type Arabidopsis inflorescencestem explant is provided as a supplemental text file. Three test results of our experiments (Figures 7 and 8 ) are also provided as a supplemental Excel file (Force and displacement.xls). For the plot between mass per length and stiffness, see Figure 9 .

\section{$\underline{\text { Notes }}$}

1. The tensile testing machine, $A C-500 \mathrm{~N}-\mathrm{CM}$, was exported from Japan to destinations such as Singapore and Thailand before. English manual is available for the operation of this machine with a computer. Other tensile testing machines are also available in the local manufacturer in your country such as Instron (https://www.instron.us/en-us). The detailed performance of the tensile testing machine in our laboratory is shown in Table 1. 
Table 1. Performance of the tensile testing machine AC-500N-CM

\begin{tabular}{ll}
\hline Loading system & Closed loop digital servo mechanism by computer (Windows 10) \\
\hline Loading capacity: & Maximum: $500 \mathrm{~N}$ (50 kgf) \\
Effective test width: & $200 \mathrm{~mm}$ \\
Crosshead stroke: & $490 \mathrm{~mm}$ \\
Effective stroke: & $250 \mathrm{~mm}$ \\
Crosshead-performance & \\
Operation: & Auto and manual operations are available. \\
Speed range: & $0.01-500$ mm/min \\
Accuracy & $\pm 0.2 \%$ of indicated value \\
Displacement resolution: & 5 -digit display, \pm 00.000 mm to \pm 99.999 mm (X-T-mode) \\
Return-speed: & $0.1-500$ mm/min \\
Load-performance & \\
Load cell: & $10 \mathrm{~N}(1 \mathrm{kgf})$ as maximum force level \\
Load range: & 7 steps (1, 2, 5, 10, 20, 50, and 100\%) or full auto range \\
Accuracy: & $\pm 1 \%$ of indicated value within 1-100\% of load range \\
Load resolution: & 5 -digit display, 0.001-10.000 N \\
Load calibration: & Auto-zero and auto-spanning functions \\
Overload protection & Yes, Auto-stop function works at 102\% of full scale. \\
Sample break detection & Yes \\
Stroke Limiter & 2 points at upper or lower position \\
Dimensions & 390 (W) x 410 (D) x 720 (H) mm \\
\hline
\end{tabular}

2. We used seventeen plants in the wild type, twenty-seven plants in nst1nst3 mutant line, fifteen to twenty-two plants for each of four independent lines of transgenic NST3 promoter-driven ERF035-VP16 (120 plants in total) in the previous publication (Sakamoto et al., 2018).

3. The heat treatment with methanol kills the inflorescence stem and deactivates endogenous cell wall hydrolases. However, expansin, a wall loosening protein remains active in this treatment (Cosgrove, 2011). There is a method to remove protoplasts from plant tissues without using methanol if it is required to see in-vitro effects of exogenously applied expansin or glycosyl hydrolase on the mechanical properties (Cosgrove, 2011). Non-metal materials for the fiber clamps in the tensile testing machine were recommended in some experiments (Cosgrove, 2011). If unexpected results of the mechanical properties are obtained, fixation method of tissues and the appropriate material for the clamps may need to be considered.

4. Pronase $E$ (Actinase $E$ ) is a nonspecific protease (Nomoto et al., 1960) and generally used for the removal of proteins from the polysaccharide samples (Schmidt et al., 2014; Higashi et al., 2015). This treatment removes the remaining cytoplasmic proteins and cell wall proteins including expansins from the explants. According to Cleland (1967), pronase treatment removed $85-90 \%$ of total protein from the stem explants, which was measured by either Kjeldahl nitrogen or proline, but it was less effective to solubilize the structural wall protein such as extensin; only $45 \%$ of the hydroxyproline was removed. 
5. If the tightening by the hand screw is not appropriate (too strong or too weak), a slippage or breakdown of the sample could be observed during the loading of the sample (Figure 10).

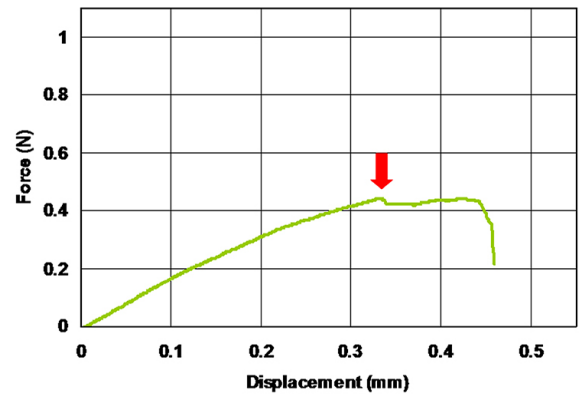

Figure 10. Example of a sample slippage or breakdown. Arrow indicates the displacement where the slippage or the breakdown of the sample has occurred.

6. Dry weight of inflorescence explants (ca. $30 \mathrm{~mm}$ in longitudinal length) ranged from 1.02 to 4.91 $\mathrm{mg}$ in our experiments. Therefore, we need an analytical balance equipped with an anti-static apparatus and a custom-made wind-proof cover to achieve the stable measurement of the dry weight for each sample (Figure 11).

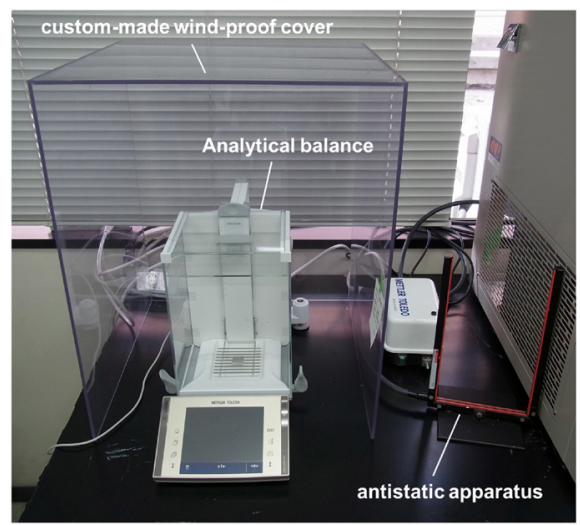

Figure 11. Analytical balance with custom-made wind-proof cover and antistatic apparatus

7. The obtained equation is also available to calculate the cell wall compliances of tissues by using the mass per unit length as an arbitrary unit of the cross-sectional area (Cleland, 1967). The cell wall compliance is a reciprocal of Young's modulus. If each sample is loaded twice to obtain first and second force extension curves, compliances of elastic extensibility and plastic extensibility can be determined from these two curves (Masuda, 1969; Cleland, 1984; Park and Cosgrove, 2012; Phyo et al., 2017). 


\section{$\underline{\text { Recipes }}$}

1. Potassium phosphate buffer for PE

a. Dissolve $14.3 \mathrm{~g} \mathrm{KH}_{2} \mathrm{PO}_{4}$ and $25.5 \mathrm{~g} \mathrm{~K}_{2} \mathrm{HPO}_{4}$ into SDW and adjust the entire volume to 500 $\mathrm{ml}$ to obtain $0.5 \mathrm{M}$ potassium phosphate buffer $(\mathrm{pH} 7.0)$

b. Autoclave the buffer stock at $121^{\circ} \mathrm{C}$ for $15 \mathrm{~min}$

2. PE solution

a. PE powder bottle must be at room temperature before use to avoid its moisture absorption

b. Dissolve $0.02 \mathrm{~g}$ of PE powder in $85 \mathrm{ml}$ of SDW

c. Add $5 \mathrm{ml}$ of ethanol and $10 \mathrm{ml} 0.5 \mathrm{M}$ potassium phosphate buffer stock

d. The prepared PE solution should be incubated for $2 \mathrm{~h}$ at $37^{\circ} \mathrm{C}$ to deactivate possibly contaminating glycosyl hydrolases

e. After incubation, use PE solution for the protein removal from tissue explants

\section{Acknowledgments}

We appreciate T. Kuroki, S. Watanabe, Y. Ono (TS-engineering Co. Ltd.), A. Nabeshima (Soft-brain Co. Ltd.) and A. Tanaka (BLW Co. Ltd.) for their technical support of the tensile testing machine. We also thank A. Hosaka, Y. Sugimoto, Dr. H. Takasaki and M. Yamada for technical support of plant material preparation. This protocol was made by optimizing the procedure for tensile tests performed by Dr. Yoshio Masuda, professor emeritus of Osaka City University (1928.01.01-2017.03.22) and his colleagues. K.Y. appreciates Dr. Chikashi Shimoda and Dr. Masayuki Katsumi for kindly providing the information of Dr. Y. Masuda. This work was supported by the JST ALCA program (grant no. JPMJAL1107) and JSPS KAKENHI Grant Number JP18H02259 to N.M.

\section{Competing interests}

The authors declare no competing interests.

\section{References}

1. Burgert, I., Frühmann K., Keckes, J., Fratzl, P. and Stanzl-Tschegg, S. E. (2003). Microtensile testing of wood fibers combined with video extensometry for efficient strain detection. Holzforschung 57(6): 661-664.

2. Cleland, R. E. (1967). Auxin and the mechanical properties of the cell wall. Ann NY Acad Sci 144(1): 3-18.

3. Cleland, R. E. (1984). The Instron technique as a measure of immediate-past wall extensibility. Planta 160(6): 514-520.

4. Cosgrove, D. J. (2011). Measuring in vitro extensibility of growing plant cell walls. Methods Mol 
Biol 715: 291-303.

5. Higashi, K., Okamoto, Y., Mukuno, A., Wakai, J., Hosoyama, S., Linhardt, R. J. and Toida, T. (2015). Functional chondroitin sulfate from Enteroctopus dofleini containing a 3-O-sulfo glucuronic acid residue. Carbohydr Polym 134: 557-565.

6. Masuda, Y. (1969). Auxin-induced expansion in relation to cell wall extensibility. Plant Cell Physiology 10(1):1-9.

7. Masuda, Y. (1990). Auxin-induced cell elongation and cell wall changes. J Plant Res 103: 345.

8. Mitsuda, N., Iwase, A., Yamamoto, H., Yoshida, M., Seki, M., Shinozaki, K. and Ohme-Takagi, M. (2007). NAC transcription factors, NST1 and NST3, are key regulators of the formation of secondary walls in woody tissues of Arabidopsis. Plant Cell 19(1): 270-280.

9. Nakata, M. T., Takahara, M., Sakamoto, S., Yoshida, K. and Mitsuda, N. (2018). Highthroughput analysis of Arabidopsis stem vibrations to identify mutants with altered mechanical properties. Front Plant Sci 9: 780.

10. Niklas, K.J. and Moon, F. C. (1988). Flexural stiffness and modulus of elasticity of flower stalks from Allium stalks from Allium sativum as measured by multiple resonance frequency spectra. Am J Bot 75(10): 1517-25.

11. Nomoto, M., Narahashi, Y. and Murakami, M. (1960). A proteolytic enzyme of streptomyces griseus: VI. hydrolysis of protein by strepomyces griseus protease. J Biochem 48(4): 593-602.

12. Olson, A. C., Bonner, J. and Morré, D. J. (1965). Force extension analysis of Avena coleoptile cell walls. Planta 66(2): 126-134.

13. Park, Y. B. and Cosgrove, D. J. (2012). Changes in cell wall biomechanical properties in the xyloglucan-deficient xxt1/xxt2 mutant of Arabidopsis. Plant Physiol 158(1): 465-475.

14. Phyo, P., Wang, T., Kiemle, S. N., O'Neill, H., Pingali, S. V., Hong, M. and Cosgrove, D. J. (2017). Gradients in wall mechanics and polysaccharides along growing inflorescence stems. Plant Physiol 175(4): 1593-1607.

15. Radotić, K., Roduit, C., Simonovic, J., Hornitschek, P., Fankhauser, C., Mutavdzic, D., Steinbach, G., Dietler, G. and Kasas, S. (2012). Atomic force microscopy stiffness tomography on living Arabidopsis thaliana cells reveals the mechanical properties of surface and deep cellwall layers during growth. Biophys $J$ 103(3): 386-394.

16. Sakamoto, S., Somssich, M., Nakata, M. T., Unda, F., Atsuzawa, K., Kaneko, Y., Wang, T., Bagman, A. M., Gaudinier, A., Yoshida, K., Brady, S. M., Mansfield, S. D., Persson, S. and Mitsuda, N. (2018). Complete substitution of a secondary cell wall with a primary cell wall in Arabidopsis. Nat Plants 4(10): 777-783.

17. Schmidt, E. P., Li, G., Li, L., Fu, L., Yang, Y., Overdier, K. H., Douglas, I. S. and Linhardt, R. J. (2014). The circulating glycosaminoglycan signature of respiratory failure in critically ill adults. $J$ Biol Chem 289(12): 8194-8202.

18. Shah, D. U., Reynolds, T. P. S. and Ramage, M. H. (2017). The strength of plants: theory and experimental methods to measure the mechanical properties of stems. J Exp Bot 68(16): 44974516. 
19. Strabala, T. J. and Macmillan, C. P. (2013). The Arabidopsis wood model-the case for the inflorescence stem. Plant Sci 210: 193-205.

20. Taiz, L. (1984). Plant cell expansion: regulation of cell wall mechanical properties. Ann Rev Plant Physiol 35: 585-657. 